\title{
Alometric Model for Estimation of Leaf Area of Garcinia brasiliensis Mart. Through Non-destructive Method
}

\author{
Vinicius de Souza Oliveira ${ }^{1}$, Cássio Francisco Moreira de Carvalho ${ }^{1}$, Juliany Morosini França ${ }^{1}$, \\ Flávia Barreto Pinto ${ }^{1}$, Karina Tiemi Hassuda dos Santos ${ }^{2}$, Jéssica Sayuri Hassuda Santos ${ }^{2}$, \\ Gleyce Pereira Santos ${ }^{2}$, Ana Paula Braido Pinheiro ${ }^{1}$, Omar Schmildt ${ }^{1}$, Marcio Paulo Czepak ${ }^{2}$, \\ Sara Dousseau Arantes ${ }^{3}$, Rodrigo Sobreira Alexandre ${ }^{4}$, José Augusto Teixeira do Amaral ${ }^{4}$, \\ Edney Leandro da Vitória ${ }^{2} \&$ Edilson Romais Schmildt ${ }^{2}$ \\ ${ }^{1}$ Postgraduate Program in Tropical Agriculture, Federal University of Espírito Santo, São Mateus, ES, Brazil \\ ${ }^{2}$ Departament of Agrarian and Biological Sciences, Federal University of Espírito Santo, São Mateus, ES, Brazil \\ ${ }^{3}$ Capixaba Institute for Research, Technical Assistance and Rural Extension, Regional Center for Rural \\ Development, Brazil \\ ${ }^{4}$ Federal University of Espírito Santo, Alegre, ES, Brazil \\ Correspondence: Vinicius de Souza Oliveira, Postgraduate Program in Tropical Agriculture, Federal University \\ of Espírito Santo, São Mateus, ES, Brazil. E-mail: souzaoliveiravini@gmail.com
}

Received: April 1, 2019

doi:10.5539/jas.v11n10p154
Accepted: May 13, $2019 \quad$ Online Published: July 15, 2019

URL: https://doi.org/10.5539/jas.v11n10p154

\begin{abstract}
The objective of the present study was to test and establish mathematical models to estimate the leaf area of Garcinia brasiliensis Mart. through linear dimensions of the length, width and product of both measurements. In this way, 500 leaves of trees with age between 4 and 6 years were collected from all the cardinal points of the plant in the municipality of São Mateus, North of the State of Espírito Santo, Brazil. The length (L) along the main midrib, the maximum width (W), the product of the length with the width (LW) and the observed leaf area (OLA) were obtained for all leaves. From these measurements were adjusted linear equations of first degree, quadratic and power, in which OLA was used as dependent variable as function of L, W and LW as independent variable. For the validation, the values of $\mathrm{L}, \mathrm{W}$ and $\mathrm{LW}$ of 100 random leaves were substituted in the equations generated in the modeling, thus obtaining the estimated leaf area (ELA). The values of the means of ELA and OLA were tested by Student's t test $5 \%$ of probability. The mean absolute error (MAE), root mean square error (RMSE) and Willmott's index $\mathrm{d}$ for all proposed models were also determined. The choice of the best model was based on the non significant values in the comparison of the means of ELA and OLA, values of MAE and RMSE closer to zero and value of the index $d$ and coefficient of determination $\left(\mathrm{R}^{2}\right)$ close to unity. The equation that best estimates leaf area of Garcinia brasiliensis Mart. in a way non-destructive is the power model represented by por $\mathrm{ELA}=0.7470(\mathrm{LW})^{0.9842}$ and $\mathrm{R}^{2}=0.9949$.
\end{abstract}

Keywords: Garcinia brasiliensis Mart., mathematical models, modeling of leaf area, foliar allometry

\section{Introduction}

The species Garcinia brasiliensis Mart. (Rheedia brasiliensis Planch e Triana), belonging to the family Clusiaceae, commonly known as bacuri, bacupari, porocó and bacuripari, is a native of the Amazon region and having specimens spread throughout the Brazilian territory, being an important source of food for the fauna, as well as use as raw material for medicine (Oliveira, Ribeiro, Matias, Gusmão, \& Pereira, 2011). Its therapeutic potential and its compounds provide multiple medicinal activities such as antianphylactic, antimicrobial, antispasmodic, anti-inflammatory, antioxidant, antiproteolytic, antiproliferative and leishmanicidal (Pereira et al., 2010; Santa-Cecília et al., 2013).

Allometry in determining leaf area is an important biological attribute of plant growth, which affects biological and economic productivity (Schwab et al., 2014). It is possible to estimate the transpiration intensity, net assimilation rate, leaf area ratio, specific leaf area and leaf area index, in addition, quantifies variations in growth due to genetic or environmental changes (Marrocos et al., 2010).

The estimation of the leaf area can be done by direct and indirect methods. The direct methods involve the 
measurement of a representative amount of leaves that must be harvested from the plants, thus these methods in most cases are destructive (Toebe, Brum, Lopes, Filho, \& Silveira, 2010). On the other hand, the indirect methods are non-destructive of easy and fast measurement, that can be realized in field and in several periods of the same plant, being possible to follow its vegetative development (Aquino, Santos Júnior, Guerra, \& Costa, 2011).

Among the indirect methods, the obtaining of mathematical models is a technique that has been reported due to the speed, ease and applicability for the determination of the leaf area for several species as Vitis vinifera L. (Montero, Juan, Cuesta, \& Brasa, 2000), Helianthus annuus L. (Rouphael, Colla, Fanasca, \& Karam, 2007), cafeeiro (Antunes, Pompelli, Carretero, \& Damatta, 2008), Crambe abyssinica (Toebe et al., 2010), Jatropha curcas (Pompelli et al., 2012), Crotalaria juncea (Carvalho, Toebe, Tartaglio, Bandeira, \& Tambara, 2017), Prunus armeniaca L. (Cirillo et al., 2017) and Guava (Vitória et al., 2018).

However, research on allometric measurements in leaf area is not available in the literature for Garcinia brasiliensis Mart. Its attainment, can become a viable and sustainable instrument, without the need to cause damage to other plants. Thus, the objective of this work was to test and establish the best mathematical model for estimating the leaf area of Garcinia brasiliensis Mart. based the length, the width and the product of the length and the width of the leaves.

\section{Method}

The present study was conducted with leaves of Garcinia brasiliensis Mart. collected in the municipality of São Mateus, North of Espírito Santo State, Brazil (18 40'36" south latitude and 39 $5^{\prime} 35^{\prime \prime}$ east longitude). The region is characterized by the tropical AW climate according to the köppen classification, with dry winter and summer rainfall (Alvares, Stape, Sentelhas, Gonçalves, \& Sparovek, 2014).

A total of 500 leaves were collected from trees aged 4 to 6 years old from all stages of development at four cardinal points, with no lesions in the limbus. The leaves were conditioned in plastic bags and transferred to the laboratory where the length (L) along the central midrib was determined in $\mathrm{cm}$, maximum leaf width (W) in $\mathrm{cm}$, product of length with width (LW) and area observed leaf (OLA) for all leaves.

For the measurement of L, the portion that went from the insertion of the petiole to the apex of the leaf was considered, W was measured through the largest width of the leaf blade (Figure 1), both measurements were made with the aid of a ruler graduated in mm. LW was obtained after the multiplication of the values of $\mathrm{L}$ and $\mathrm{W}$. Subsequently, OLA values were determined by image processing obtained from the scanning of sheets by HP Deskjet $F 4280^{\circledR}$ scanner, saved in TIFF (Tag Image File Format) with 75 dpi and analyzed through Image ${ }^{\circledR}$ software (Schindelin, Rueden, Hiner, \& Eliceiri, 2015).

L

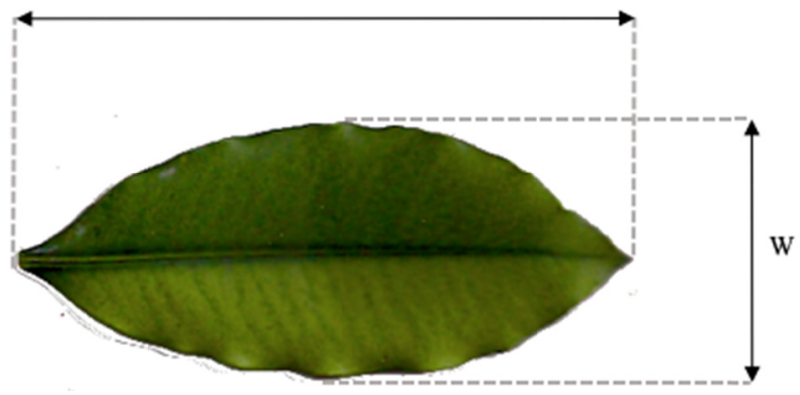

Figure 1. Representation of the length (L) along the midrib and the maximum width (W) of leaves of Garcinia brasiliensis Mart

The descriptive statistics were determined with the maximum, minimum, mean, amplitude, standard deviation and coefficient of variation (CV) values for all measures obtained. The leaves were separated into two groups, 400 used to adjust regression equations using different mathematical models to estimate the leaf area and the other 100 were used to validate the equations obtained.

Nine equations were obtained to estimate the leaf area of Garcinia brasiliensis Mart. through the linear models of first degree represented by ELA $=\widehat{\beta}_{0}+\widehat{\beta}_{1} \mathrm{x}$, quadratic represented by ELA $=\widehat{\beta}_{0}+\widehat{\beta}_{1} \mathrm{x}+\widehat{\beta}_{2} \mathrm{x}^{2}$ and power 
represented by ELA $=\widehat{\beta}_{0} x^{\hat{\beta}_{1}}$, in which OLA was used with dependent variable $(y)$ as a function of L, W and LW with independent variable $(\mathrm{x})$.

A validation test was performed for the nine equations obtained from the proposed models for leaf area estimation. The L, W and LW values of the 100 leaves used for the validation were replaced in their respective equations generated in the modeling, thus obtaining the estimated leaf area (ELA, in $\mathrm{cm}^{2}$ ) of each equation, and thus a simple linear regression equation and its respective coefficient of determination $\left(\mathrm{R}^{2}\right)$ were adjusted where ELA was used as dependent variable and OLA as independent variable. The means obtained from ELA and OLA were compared by Student's $t$ test at $5 \%$ of probability. The mean absolute error (MAE), root mean square error (RMSE) and Willmott's index d (Willmott, 1981) were calculated for each equation using Equations 1, 2 and 3.

$$
\begin{gathered}
\text { MAE }=\frac{1}{\mathrm{n}-1} \sum_{\mathrm{i}=1}^{\mathrm{n}}|\mathrm{ELA}-\mathrm{OLA}| \\
\mathrm{RMSE}=\sqrt{\frac{1}{\mathrm{n}-1} \sum_{\mathrm{i}=1}^{\mathrm{n}}(\mathrm{ELA}-\mathrm{OLA})^{2}} \\
\mathrm{~d}=1-\left[\frac{\sum_{\mathrm{i}=1}^{\mathrm{n}}\left(\mathrm{ELA}_{\mathrm{i}}-\mathrm{OLA} \mathrm{A}_{\mathrm{i}}\right)^{2}}{\sum_{\mathrm{i}=1}^{\mathrm{n}}\left(\left|\mathrm{ELA} \mathrm{A}_{\mathrm{i}}-\overline{\mathrm{OLA}}\right|+\left|\mathrm{OLA} \mathrm{A}_{\mathrm{i}}-\overline{\mathrm{OLA}}\right|\right)^{2}}\right]
\end{gathered}
$$

In that, ELA is the estimated leaf area; OLA is the observed value of leaf area; $\overline{\mathrm{OLA}}$ is the average of the leaf area values observed; and $\mathrm{n}$ is the number of sheets sampled $(\mathrm{n}=100)$.

The choice of the model that best estimates the leaf area of Garcinia brasiliensis Mart. in function of L, W and LW was based on non-significant values of the comparative means of ELA and OLA, values of MAE and RMSE closer to zero and index $\mathrm{d}$ closer to the unit. Statistical analyzes were performed using the software $\mathrm{R}$ (R Core Team, 2018), by the data package ExpDes.pt version 1.2 (Ferreira, Cavalcanti, \& Nogueira, 2018).

\section{Results and Discussion}

Table 1 shows the descriptive statistics for the characteristics length (L), width (W), product of length with width (LW) and leaf area observed (OLA). The values of L, W and LW of the leaves used for the validation are among the values of the measures of the leaves used for the modeling. According to Levine, Stephan, and Szabat (2017). for good representativeness it is necessary that the validation measures do not extrapolate the minimum and maximum measures used for the adjustment of the regression equations.

The samples used for modeling and for validation presented considerable amplitude, being proved by the high coefficient of variation (CV) values exceeding $17 \%$. This high $\mathrm{CV}$ is fundamental for studies that seek the establishment of mathematical models for the estimation of leaf area by indicating greater heterogeneity of the data sampled, portraying the presence of small, medium and large leaves, characterizing all stages of plant phenological development. Regarding the standard deviation, the LW characteristic presented the highest values, indicating a larger variation of the sample data. This same behavior was also observed by Vitória et al. (2018), studying mathematical models for the estimation of guava leaf area.

Table 1. Descriptive statistics with value maximum, minimum, mean, amplitude, standard deviation and coefficient of variation (CV) of the variables: length (L); width (W); product of the length and width (LW) of leaves of Garcinia brasiliensis Mart

\begin{tabular}{lllll}
\hline Statistic & L & W & LW & OLA \\
\hline 400 leaves were used for modeling & & & & \\
Maximum & 18.30 & 9.40 & 171.08 & 119.96 \\
Minimum & 5.20 & 2.00 & 11.96 & 8.94 \\
Mean & 12.16 & 4.95 & 63.40 & 44.3 \\
Amplitude & 13.10 & 7.40 & 159.12 & 111.02 \\
Standard deviation & 2.66 & 1.35 & 29.17 & 20.10 \\
CV(\%) & 21.93 & 27.30 & 46.01 & 44.39 \\
\hline I00 leaves for validation & & & & \\
Maximum & 16.10 & 8.40 & 125.16 & 93.13 \\
Minimum & 5.40 & 2.30 & 12.42 & 8.94 \\
Mean & 12.09 & 4.92 & 61.47 & 43.87 \\
Amplitude & 10.70 & 6.10 & 112.74 & 84.19 \\
Standard deviation & 2.06 & 1.12 & 22.54 & 15.89 \\
CV(\%) & 17.08 & 22.70 & 36.68 & 36.23 \\
\hline
\end{tabular}


The equations proposed for the estimation of the leaf area of Garcinia brasiliensis Mart. from the interpolation between the dependent variable and the independent variables and their respective determination coefficient values $\left(R^{2}\right)$ are presented in Table 2 . Note that all equations presented high values of $R^{2}$, higher than 0.89 , and the three models obtained from OLA in function of LW as independent variable presented values equal to each other and higher than the others. Similar results correlating higher coefficient of determination with the independent LW variable were also found for Vitis vinifera L. (Buttaro, Rouphael, Rivera, Colla, \& Gonnella, 2015) and Prunus armeniaca L. (Cirillo et al., 2017).

However, the selection of mathematical models for estimation of leaf area should not be based exclusively on high values of the coefficient of determination, since its application can generate uncertain estimates of the leaf area (Antunes et al., 2008). Thus, the validation of the equations by correct validation methods is fundamental practice in the choice of the best model (Fascella, Darwich, \& Rouphael, 2013).

Table 2. Equation with linear adjustment of first degree, quadratic and power and its respective coefficient of determination $\left(\mathrm{R}^{2}\right)$ using the observed leaf area (OLA) as dependent variable, in function of length $(\mathrm{L})$, width (W), product of length with width (LW) of leaves Garcinia brasiliensis Mart

\begin{tabular}{lll}
\hline Model & Equation & $\mathrm{R}^{2}$ \\
\hline Linear & ELA $=-42.6228+7.1489(\mathrm{~L})$ & 0.8989 \\
Linear & ELA $=-27.9119+14.5982(\mathrm{~W})$ & 0.9613 \\
Linear & ELA $=0.70557+0.68749(\mathrm{LW})$ & 0.9949 \\
Quadratic & ELA $=8.30487-1.83198(\mathrm{~L})+0.37610(\mathrm{~L})^{2}$ & 0.9211 \\
Quadratic & ELA $=-15.54336+9.41232(\mathrm{~W})+0.50533(\mathrm{~W})^{2}$ & 0.9648 \\
Quadratic & ELA $=0.77955232+0.68494589(\mathrm{LW})+0.00001789(\mathrm{LW})^{2}$ & 0.9949 \\
Power & ELA $=0.2048(\mathrm{~L})^{2.1297}$ & 0.9216 \\
Power & ELA $=3.1533(\mathrm{~W})^{1.6311}$ & 0.9618 \\
Power & ELA $=0.7470(\mathrm{LW})^{0.9842}$ & 0.9949 \\
\hline
\end{tabular}

The validation equations represented in Figure 2 show a high correlation between ELA and OLA in the models where LW was used as an independent variable. This high correlation can be verified by $\mathrm{R}^{2}$ values above 0.99 , indicating that more than $99 \%$ of the observed leaf area explains the estimated leaf area. Although the equations obtained with only one measurement with $\mathrm{L}$ or $\mathrm{W}$ were easier to measure in practice, they did not present a good fit in relation to OLA, in addition, according to Montero et al. (2000) this type of equation is less unstable in the determination of leaf area, and adjustments are required for different stages of vegetative development of the plants, requiring the establishment of more than one model during its cycle. 
A



D

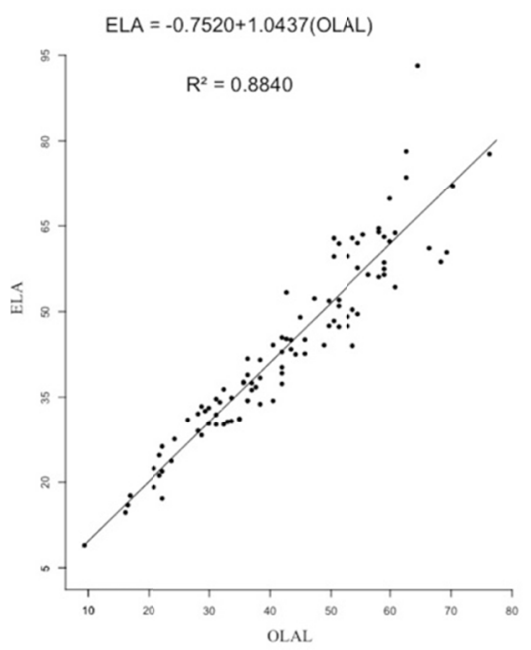

G

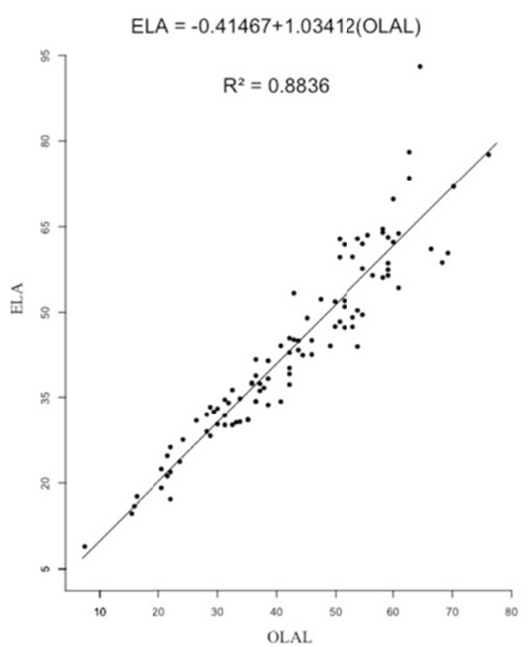

B



E

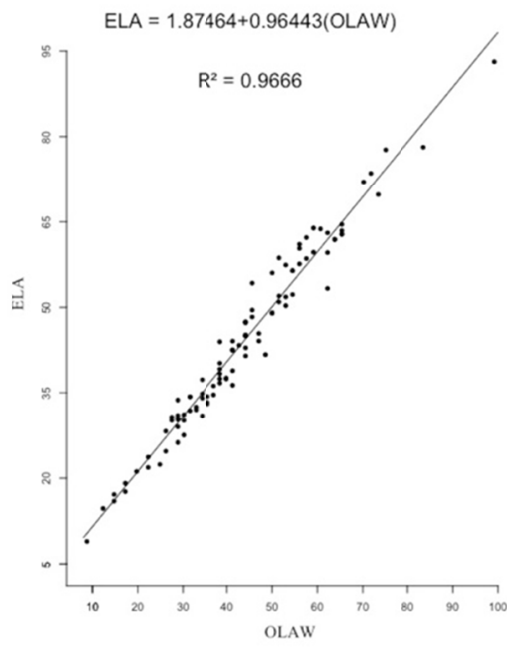

H



C

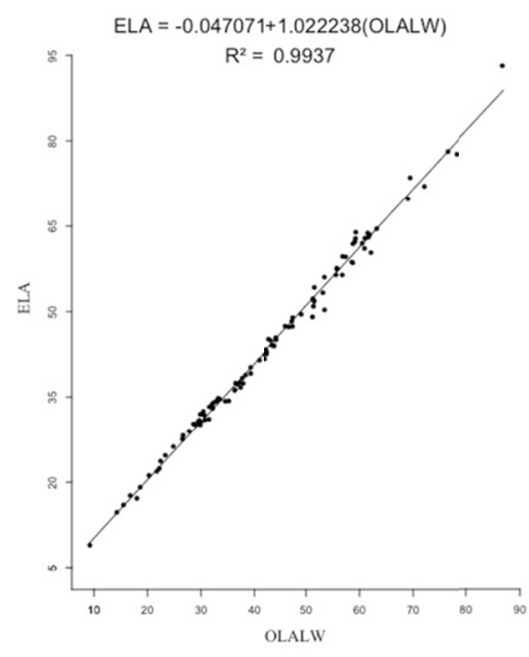

F



I



Figure 2. First degree linear adjustment validation equation and its respective determination coefficient $\left(\mathrm{R}^{2}\right)$ using the estimated leaf area (ELA) as the dependent variable obtained by first degree linear modeling equations (A, B and C), quadratic (D, E and F) and power ( $\mathrm{G}, \mathrm{H}$ and $\mathrm{I})$, as a function of leaf length observed (OLAL), width (OLAW) and length product with width (OLALW) and mean absolute error (MAE), root mean square error (RMSE) and Willmott's index d of Garcinia brasiliensis Mart. leaf 
It was observed in Table 3 that for all models the values of ELA and OLA did not differ significantly by Student's $t$ test at $5 \%$ of probability, certifying similarity between the leaf area estimated by the equations and the foliar area observed. The regression models that obtained the best values of mean absolute error (MAE), root mean square error (RMSE) and Willmott's index $d$ were those based on LW as independent variable, with index $\mathrm{d}$ being the same for all three models and MAE and RMSE slightly favorable for the power model with values closer to zero. The highest values of MAE, RMSE and lower values of the index $d$ were found using only a linear dimension ( $\mathrm{L}$ or $\mathrm{W}$ ) as independent variables, indicating that these models would be less accurate in the prediction of the leaf area of Garcinia brasiliensis Mart.

Table 3. Observed leaf area (OLA) and estimated leaf area (ELA) of linear equations of first degree, quadratic and potential for the independent variables length (L), width (W) and product of length and width (LW), besides the value of $\mathrm{p}$, mean absolute error (MAE), root mean square error (RMSE) and Willmott $\mathrm{d}$ index of leaves Garcinia brasiliensis Mart. used for validation

\begin{tabular}{|c|c|c|c|c|c|c|c|}
\hline Model & Variable & OLA & ELA & $\mathrm{p}^{*}$ value & MAE & RMSE & $\mathrm{d}$ \\
\hline Linear & $\mathrm{L}$ & & 43.8431 & 0.9887 & 4.3456 & 5.8603 & 0.9622 \\
\hline Linear & W & & 43.8382 & 0.9875 & 2.4384 & 2.9773 & 0.9914 \\
\hline Linear & LW & & 42.9655 & 0.6829 & 1.1895 & 1.5960 & 0.9974 \\
\hline Quadratic & $\mathrm{L}$ & & 42.7558 & 0.6018 & 3.9091 & 5.5651 & 0.9651 \\
\hline Quadratic & W & 43.8739 & 43.5484 & 0.8861 & 2.3872 & 2.9799 & 0.9913 \\
\hline Quadratic & LW & & 42.9597 & 0.6809 & 1.1926 & 1.5986 & 0.9974 \\
\hline Power & $\mathrm{L}$ & & 42.8274 & 0.6267 & 3.9144 & 5.5459 & 0.9656 \\
\hline Power & W & & 43.4487 & 0.8502 & 2.4137 & 3.1269 & 0.9902 \\
\hline Power & LW & & 42.9791 & 0.6877 & 1.1827 & 1.5904 & 0.9974 \\
\hline
\end{tabular}

Note. ${ }^{*} P$ values higher than 0.05 indicate that the observed leaf area (OLA) and the estimated leaf area (ELA) do not differ by Student t-test.

In specific cases with that found by Rouphael et al. (2007) for Helianthus annuus L. the one dimensional models are more accurate, however for most species models based on only one dimension are less acceptable generating erroneous estimations of the leaf area. According to Espindula et al. (2018), the combination of linear measures of the leaves as the length and the width present a greater degree of accuracy, being more desirable in studies that estimate the leaf area. Models based on the combination of linear dimensions with power adjustment as found in the present study have already been reported for coffee trees (Antunes et al., 2008) and Jatropha curcas (Pompelli et al., 2012), showing that this adjustment is more accurate to estimate the leaf area of these species.

Thus, for the estimation of the leaf area of Garcinia brasiliensis Mart. the models that required the combination of two measures provided more accurate results when compared to the models generated with only one dimension, and the model equation power $\left(\mathrm{ELA}=0.7470(\mathrm{LW})^{0.9842}\right.$ ) whose behavior is represented in Figure 3 the most indicated because it meets the validation criteria used in this study. This equation allows results to be obtained with a high degree of precision in a non-destructive way, without the need of costly equipment such as planimeter and portable scanner (Cirillo et al., 2017). 


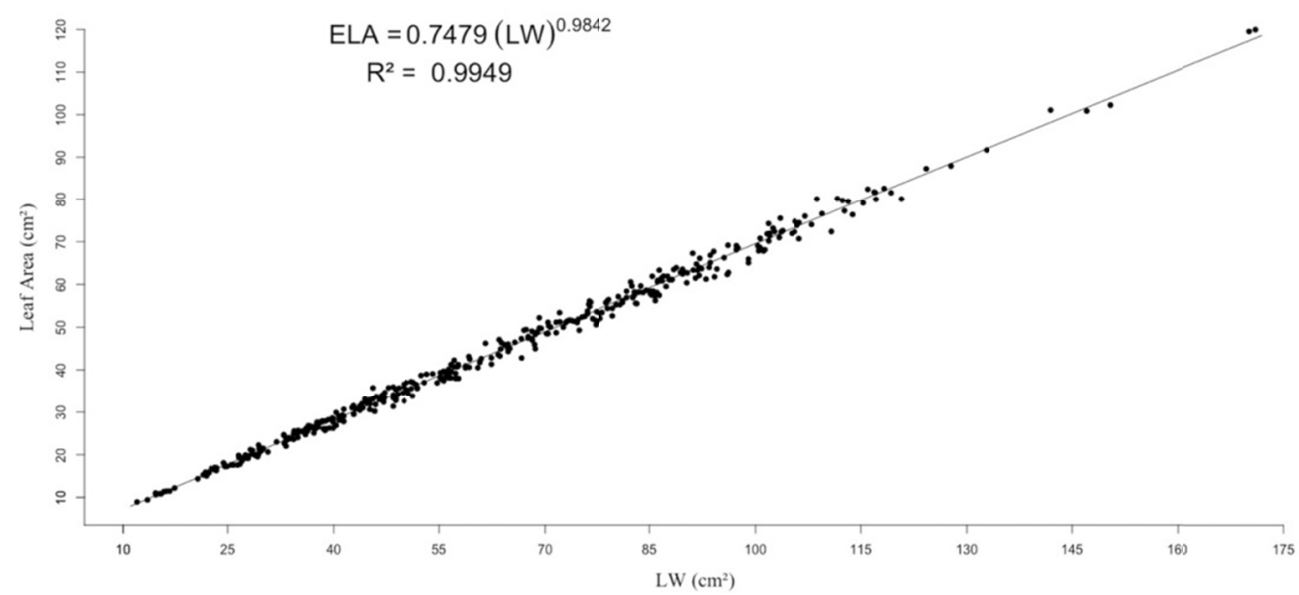

Figure 3. Equation of power model and determination coefficient (R2), using the foliar area observed (OLA) as dependent variable, in function of the product of the length and width (LW) of leaves Garcinia brasiliensis Mart

\section{Conclusion}

The power model equation based on the product of the length along the central midrib and the maximum leaf width $(\mathrm{LW})$ represented ELA $=0.7470(\mathrm{LW})^{0.9842}$ is the one that best met the criteria of this study $\left(\mathrm{R}^{2}=0.9949\right.$, MAE $=1.1827$, RMSE $=1.5904$ and $\mathrm{d}=0.9974)$ being the most suitable for the estimation of the leaf area of Garcinia brasiliensis Mart. quickly and non-destructively.

\section{Acknowledgements}

CNPq, CAPES and FAPES for financial support.

\section{References}

Aquino, L. A., Santos Júnior, V. C., Guerra, J. V. S., \& Costa, M. M. (2011). Estimates of sunflower leaf area by a non-destructive method. Bragantia, 70, 832-836. https://doi.org/10.1590/S0006-87052011000400015

Alvares, C. A., Stape, J. L., Sentelhas, P. C., Gonçalves, J. L. M., \& Sparovek, G. (2014). Köppen's climate classification map for Brazil. Meteorologische Zeitschrift, 22(6), 711-728. https://doi.org/10.1127/ 0941-2948/2013/0507

Antunes, W. C., Pompelli, M. F., Carretero, D. M., \& Damatta, F. M. (2008). Allometric models for non-destructive leaf area estimation in coffee (Coffea arabica and Coffea canephora). Annals of Applied Biology, 153(1), 33-40. https://doi.org/10.1111/j.1744-7348.2008.00235.x

Buttaro, D., Rouphael, Y., Rivera, C. M., Colla, G., \& Gonnella, M. (2015). Simple and accurate allometric model for leaf area estimation in Vitis vinifera L. genotypes. Photosynthetica, 53(3), 342-348. https://doi.org/10.1007/s11099-015-0117-2

Carvalho, J. O., Toebe, M., Tartaglio, F. L., Bandeira, C. T., \& Tambara, A. L. (2017). Leaf area estimation from linear measurements in different ages of Crotalaria juncea plants. Anais da Academia Brasileira de Ciencias, 89(3), 1851-1868. https://doi.org/10.1590/0001-3765201720170077

Cirillo, A., Pannico, A., Basile, B., Rivera, C. M., Giaccone, M., Colla, G., Pascale, S., \& Rouphael, Y. (2017). A simple and accurate allometric model to predict single leaf area of twenty-one European apricot cultivars. European Journal of Horticultural Science, 82(2), 65-71. https://doi.org/10.17660/eJHS.2017/82.2.1

Espindula, M. C., Passos, A. M. A., Araújo, L. F. B., Marcolan, A. L., Partelli, F. L., \& Ramalho, A. R. (2018). Indirect estimation of leaf area in genotypes of 'Conilon' coffee (Coffea canephora Pierre ex A. Froehner). Australian Journal of Crop Science, 12(6), 990-994. https://doi.org/10.21475/ajcs.18.12.06.PNE1090

Fascella, G., Darwich, S., \& Rouphael, Y. (2013). Validation of a leaf area prediction model proposed for rose. Chilean Journal of Agricultural Research, 73(1), 73-76. https://doi.org/10.4067/S0718-58392013000 100011

Ferreira, E. B., Cavalcanti, P. P., \& Nogueira, D. A. (2018). Package 'ExpDes.pt'.

Levine, D. M., Stephan, D. F., \& Szabat, K. A. (2017). Estatistic for managers using Microsoft Excel: Global edition (8th ed., p. 728). London: Person. 
Marrocos, S., Tarcio. P., Dantas, M. S. M., Dombroski, J. L. D., Lucena, R. R. M., \& Batista, T. M. V. (2010). Comparative analysis of methods of estimation leaf area beet. Revista Verde de Agroecologia e Desenvolvimento Sustentável, 5, 140-146.

Montero, F. J., Juan, J. A., Cuesta, A., \& Brasa, A. (2000). Non destructive Methods to Estimate Leaf Area in Vitis vinifera L. HortScience, 35(4), 696-698. https://doi.org/10.21273/HORTSCI.35.4.696

Oliveira, A. K. M., Ribeiro, J. W. F., Matias, R., Gusmão, D. H., \& Pereira, K. C. L. (2011). Allelopathic potential of fresh leaves of bacupari (Rheedia brasiliensis (Mart.) Planch. \& Triana) in germination of lettuce). Revista Brasileira de Biociências, 9(4), 550-553.

Pereira, I. O. L. R., Marques, M. J., Pavan, A. L. R., Codonho, B. S., Barbieri, C. L., Beijo, L. A., ... Santos, M. H. (2010). Leishmanicidal activity of benzophenones and extracts from Garcinia brasiliensis Mart fruits. Phytomedicine, 17, 339-345. https://doi.org/10.1016/j.phymed.2009.07.020

Pompelli, M. F., Antunes, W. C., Ferreira D. T. R. G., Cavalcante, P. G. S., Wanderley filho, H. C. L., \& Endres, L. (2012). Allometric models for non-destructive leaf area estimation of Jatropha curcas. Biomass and Bioenergy, 36, 77-85. https://doi.org/10.1016/j.biombioe.2011.10.010

R Core Team. (2018). R: A language and environment for statistical computing. Vienna, Austria: R Foundation for Statistical Computing.

Rouphael, Y., Colla, G., Fanasca, S., \& Karam, F. (2007). Leaf area estimation of sunflower leaves from simple linear measurements. Photosynthetica, 45(2), 306-308. https://doi.org/10.1007/s11099-007-0051-z

Santa-Cecília, F. V., Abreu, F. A., Silva, M. A., Castro, E. M., Santos, M. H., \& Santa-Cecilia, F. V. (2013). Pharmacobotanical studies of Garcinia brasiliensis Mart. (Clusiaceae) leaves. Rev. Bras. Plantas Med., 15, 397-404. https://doi.org/10.1590/S1516-05722013000300013

Schindelin, J., Rueden, C. T., Hiner, M. C., \& Eliceiri, K. W. (2015). The ImageJ Ecosystem: An Open Platform for Biomedical Image Analysis. Molecular Reproduction and Development, 82(7-8), 518-529. https://doi.org/10.1002/mrd.22489

Schwab, N. T., Streck, N. A., Rehbein, A., Ribeiro, B. S. M. R., Ulhmann, L. O., Langner, J, A., \& Becker, C.C. (2014). Linear dimensions of leaves and its use for estimating the vertical profile of leaf area in gladiolus. Bragantia, 73, 97-105. https://doi.org/10.1590/brag.2014.014

Toebe, M., Brum, B., Lopes, S. J, Filho, A. C., \& Silveira, T. R. (2010). Estimate leaf area of Crambe abyssinica for leaf discs and digital photos. Ciência Rural, 40(2), 445-448. https://doi.org/10.1590/S0103-84782 010000200036

Vitória, E. L., Freitas, I. L. J, Locatelli, T., Lacerda, E. G., Valle, J. M., Pereira, R. C., Almeida, P. F. P., Vitoria, R. Z., Simom, C. P, Fernandes, A. A. (2018). Mathematical Models for Leaf Area Estimates of Guava. Journal of Agricultural Science, 10(12), 272-278. https://doi.org/10.5539/jas.v10n12p272

Willmott, C. J. (1981). On the validation of models. Physical Geography, 2(2), 184-194. https://doi.org/10.1080/ 02723646.1981 .10642213

\section{Copyrights}

Copyright for this article is retained by the author(s), with first publication rights granted to the journal.

This is an open-access article distributed under the terms and conditions of the Creative Commons Attribution license (http://creativecommons.org/licenses/by/4.0/). 